\title{
CONVERSAS DOCENTES NO WHATSAPP FORJANDO APRENDIZAGENS MULTIRREFERENCIAIS E AUTORIAS DOCENTES
}

\author{
Rosana Sales de Jesus \\ Mirian Maia do Amaral
}

\section{Resumo}

Este artigo, subproduto de uma pesquisa de mestrado, realizada em uma escola pública da rede municipal do Rio de Janeiro, objetiva compreender como conversas tecidas no WhatsApp, pelos professores da educação básica, podem contribuir para seus processos formativos e autorais. Nesse intento, dialogamos com as abordagens de Alves (2008); Andrade, Caldas e Alves (2019); Certeau (2013); Santaella (2013); Santos, (2005, 2014, 2019); Silva (2003, 2014), entre outros. A metodologia inscreveu-se na bricolagem dos princípios da multirreferencialidade com a pesquisa com os cotidianos na cibercultura, o que nos possibilitou engendrar atos de currículo que fizeram emergir conversas que forjaram processos de auto, hetero, eco e trans (formação), materializados em aprendizagens e autorias diversos. Desse modo, concluímos que o uso do aplicativo pode mediar conexões entre os professores para além do uso social, instituindo-se como um espaço de ensino, aprendizagem e formação na cibercultura.

Palavras-chave: cibercultura, multirreferencialidade, cotidiano, conversas no whatsapp messenger.

\section{TEACHING CONVERSATIONS ON WHATSAPP FORGING MULTI- REFERENTIAL LEARNING AND TEACHING AUTHORSHIP}

\section{Abstract}

This article, the byproduct of a master's research, which held at a public school in the municipal network of Rio de Janeiro, aims to understand how conversations woven on WhatsApp by teachers of basic education, can contribute. for the formative and authorial process of teachers of basic education. In this attempt, we dialogue with the approaches of Alves (2008); Andrade, Caldas and Alves (2019); Certeau (2013); Santaella (2013); Santos, (2005, 2014, 2019); Silva (2003, 2014), among others. The methodology were inscribed in the bricolage of principles of multi-referentiality with everyday life in cyberculture, which allowed us to engender acts of curriculum that made conversations emerge that forged processes of self, hetero and echo and trans (formation), materialized in different learning and authorship. Thus, we conclude that the use of the application can mediate connections between teachers, beyond social use, establishing itself as a space for teaching, learning and training in cyberculture.

Keywords: cyberculture, multi-referentiality, daily, whatsapp messenger.

\section{CONVERSACIONES DE ENSEÑANZA SOBRE WHATSAPP FORJANDO AUTORÍA DE ENSEÑANZA Y APRENDIZAJE MULTIRREFERENCIAL}

Resumen

Este artículo, el subproducto de una investigación de maestría, que se realizó en una escuela pública en la red municipal de Río de Janeiro, tiene como objetivo comprender cómo las conversaciones tejidas en WhatsApp por los maestros de educación básica pueden contribuir. para el proceso formativo y autoral de los docentes de educación básica. En este intento, dialogamos con los enfoques de Alves (2008); Andrade, Caldas y Alves (2019); Certeau (2013); Santaella (2013); Santos, (2005, 2014, 2019); Silva (2003, 2014), entre otros. La metodología se inscribió en el bricolaje de principios de multirreferencialidad con la vida cotidiana 
DOI: $10.12957 /$ teias. $\%$ Y.52666

en cibercultura, que nos permitió engendrar actos curriculares que hicieron surgir conversaciones que forjaron procesos de self, hetero y echo y trans (formación), materializados en diferentes aprendizajes y varias autorías. Así, concluimos que el uso de la aplicación puede mediar las conexiones entre los docentes, más allá del uso social, estableciéndose como un espacio para la enseñanza, el aprendizaje y la formación en cibercultura.

Palabras clave: cibercultura, multireferencialidad, diário, conversaciones de whatsapp messenger.

\section{INTRODUÇÃO}

O presente artigo é fruto da parceria entre três pesquisadoras da Universidade do Estado do Rio de Janeiro. Inspirado na dissertação de mestrado de uma das autoras, realizada em 2019. que objetivou compreender como conversas e narrativas tecidas no Whats $A p p$, pelos professores da educação básica, podem contribuir para seus processos formativos e autorais (JESUS, 2019), entendendo-as como parte da multiplicidade de contextos na qual se dá a formação profissional (ALVES, 2008). Portanto, este estudo se justifica pela potência dos aplicativos na atualidade, pois com o uso do digital em rede a comunicação é mais rápida e fluída.

$\mathrm{O}$ artigo traz à cena uma escola do município do Rio de Janeiro, localizada no bairro do Cachambi, que atende ao ensino fundamental (EF) e à educação de jovens e adultos (EJA). Recebe alunos oriundos de uma comunidade carente, marcada pelo tráfico de drogas, desemprego, mercado informal e pelas questões voltadas para a juventude. Nessa ambiência, conteúdos e valores emergem sem retoques, deixando expostas as questões culturais, os riscos ao meio ambiente e à saúde da população, a falta de políticas públicas de revitalização local, que interferem, de forma significativa, nesse cotidiano.

Em 2016, a diretora da escola criou um grupo no aplicativo WhastApp Messenger, tendo em vista reorganizar a unidade escolar, regularizar questões administrativas, e conversar com os professores sobre projetos que possibilitassem o acesso e a permanência do aluno na escola. Logo, esse uso foi ressignificado pelos docentes, que passaram a estender os bate-papos aligeirados que aconteciam, presencialmente durante o horário escolar, para essa ambiência formacional.

Começamos, então, a ter acesso ao que se produzia, na escola ou fora dela, anteriormente restrito ao espaço das salas de aula ou às exposições dos trabalhos nos murais da escola. Nas conversas no aplicativo, alguns professores narravam o vivido, e motivavam seus pares a entrar nessa rede de produção coletiva, "[...] ampliando os processos educativos para além dos encontros face a face" (SANTOS, 2014, p. 74). Assim, a escola entra nas redes tecidas em nós narrativos, que nos formam: nós da rede, nós em rede!

Em tempos de distanciamento físico e, possibilitados pelas tecnologias móveis e ubíquas, somos inspirados a estar em rede, de forma ativa, refletindo sobre temas emergentes, tecendo considerações diversas, avaliando, rotulando e narrando acontecimentos e experiências.

Os aplicativos ou $A p p$ (abreviatura do termo application, em inglês) vieram para facilitar a vida das pessoas. Assim, com um smartphone nas mãos, entre outras ações, podemos conversar em rede, comprar, vender, assistir a filmes e ouvir músicas, além de produzir narrativas textuais, imagéticas e sonoras. Desse modo, não nos limitamos ao consumo, mas interagimos, na busca de sentido e significação para aquilo que pensamos e fazemos, produzindo e compartilhando conhecimentos em rede.

Não apenas a ciência moderna entende a conversa como algo distante da objetividade, retirando de cena o prosear como possibilidade de método de investigação científica, mas ditados populares, como 'Quem conta um conto, aumenta um ponto'; 'Conversa pra boi dormir'; 'Jogar 
conversa fora'; 'Em boca fechada não entra mosca'; entre outros ditos, também conferem à conversa sentidos múltiplos. Entretanto, poucos são os que a elogiam, dizendo: 'É conversando que se entende'.

No entanto, a conversa faz parte da vida cotidiana da sociedade, constituindo o meio de interação social predominante e a principal via de socialização, ainda que, na academia, ela geralmente seja "[...] aprisionada e cristalizada sob a égide de um script materializado por nomes diversos: entrevista, questionário, grupo focal, testes, dinâmicas e correlatos" (SPINK et al., 2014, p. 100).

Entendemos que conversar é valorizar lugares de vivência, de diversidade, de diálogo e de encontro. Portanto, é estar com o outro, é conviver, é falar sobre os mais diversos assuntos, estabelecendo nessa troca uma relação de proximidade e partilha.

O ambiente escolar é lugar prenhe de conversas: na sala de aula, alunos conversam entre si, professores recebem seus pares, partilham seus dilemas e sonhos. Na cozinha, a 'tia da merenda' fala com a diretora, enquanto o cheiro da comida exala pelos corredores. Alguém olha o celular, após receber uma mensagem pelo Whats $A p p$ : é a direção da escola avisando que alguns pais estão vindo buscar os filhos mais cedo, pois há conflito na comunidade. Respiramos e inspiramos histórias que emergem das conversas tecidas nos "espaçostempos" escolares. Algumas delas desenham o rumo de nossas ações cotidianas. Como, então, ignorar os sentidos e significados expressos em cada conversa?

Segundo Recuero (2009), uma rede social, como o Facebook, o Instagram e o Whats App (dispositivo de nossa pesquisa) é constituída por um conjunto de pessoas, instituições ou grupos (os nós da rede, e suas conexões), interações ou laços sociais. Criado em 2014, o Whats App ganhou projeção por ser um aplicativo de mensagem multiplataforma com opções de (a) envio e recebimento de mensagens instantâneas; (b) criação de grupos para compartilhamento de arquivos; (c) acesso por qualquer computador, desde que o usuário possua uma conta ativa no aplicativo em seu celular. No entanto, o ponto marcante desse dispositivo reside no fato de possibilitar o envio de textos escritos, ou com emojis ${ }^{2}$, além de fotos, imagens diversas, e gravações de áudio e vídeos.

Nesse cenário, professores e alunos necessitam vivenciar uma escola do seu tempo, realizando reflexões sobre o cotidiano, criando alternativas que promovam o uso dos aplicativos para potencializar a formação e autorias "[...] na produção de narrativas no ciberespaço" (COUTO, PORTO, SANTOS, 2016, p. 12).

Devido a sua popularidade, o uso do Whats $A p p$ vem sendo intensificado nas escolas, permitindo que, numa relação dialógica, interativa e colaborativa, os estudantes fundamentem e defendam pontos de vistas, elaborem pesquisas extraclasse, de forma mais autônoma, o que torna o processo de "aprendizagemensino" mais prazeroso.

Reconhecer o WhatsApp como um dispositivo de conversas cotidianas e espaço de aprendizagens diversas é fundamental para pensarmos as práticas que emergem nessa ambiência, o

\footnotetext{
${ }^{1}$ Esse termo e tantos outros que ainda aparecerão neste texto, estão assim grafados porque, há muito, percebemos que as dicotomias necessárias à criação das ciências na Modernidade têm significado limites ao que precisamos criar na corrente de pesquisa a que pertencemos. Com isto, passamos a grafar deste modo os termos de dicotomias herdadas: juntos, em itálico e entre aspas [...] (ANDRADE, CALDAS, ALVES, 2019, p. 19-20).

${ }^{2}$ Emojis é um conjunto de figuras que ilustra alguns tipos básicos de emoções humanas. Às vezes, os emojis enviados a alguém são substituídos por quadradinhos brancos; o que significa que o aparelho ou programa que se está usando não foi atualizado para suportar aquele caractere.
} 
DOI: $10.12957 /$ teias.\%Y.52666

que demanda exercitar o sentido de alteridade e se abrir ao outro e a sua fala, mediante uma 'escuta sensível'3 (BARBIER, 2007).

${ }^{3}$ Diz respeito a um modo de tomar consciência e de intervir, baseado na sensibilidade do pesquisador; uma atitude que procura ver e compreender os sujeitos como seres capazes competentes e complexos, dotados de saberes, abarcando a experiência e suas transformações formativas (COLACIQUE, 2018). 


\section{O PERCURSO METODOLÓGICO DA PESQUISA COM UM RIGOR OUTRO}

É incontestável a popularidade do WhatsApp, especialmente entre jovens, dada a possibilidade de enviar textos escritos, mensagens de voz, além de imagens estáticas ou em movimento, sem limites de tempo e espaço. Plugar-se a esse aplicativo é ampliar as possibilidades de interação, mediante a formação de grupos que se aproximam para trocar mensagens instantâneas e privadas. Nesse contexto, as pessoas com as quais conversamos "[...] nos afetam e são afetadas, porque compreendem que o dizer das outras pessoas é importante, porque as pessoas que falam são ou tornaram-se - com o deslocar no tempoespaço - importantes", como afirma Serpa (2010, p.76). No entanto, enfatizamos, essas conversas não são isentas de conflitos, ruídos, faltas e tensões.

Como, então, realizar a pesquisa acadêmica a partir de um dispositivo, dinâmico e desafiador, como o Whats App?

Em face das incertezas contemporâneas faz-se necessário um 'olhar plural' que rompa com a hegemonia epistemológica do pensamento moderno, fragmentado, reducionista, e um tanto rígido, na busca de um rigor outro, que nos possibilite lidar com a impureza, com o inacabado, com a incompletude e com a opacidade tão necessárias às ciências humanas.

Para Santos, (2005, p. 140) é "[...] fundamental vivenciar uma metodologia aberta às emergências, ao novo, ao possível, ao acontecimento", a partir de uma epistemologia participativa e implicada, vivenciada no movimento "práticateoriaprática".

Desse modo, ao iniciarmos nossa pesquisa, e diante das inúmeras inquietações que movem o desejo de busca por respostas, o caminho metodológico que nos pareceu mais adequado foi a proposta da pesquisa multirreferencial bricolada aos cotidianos na cibercultura, que não separa o sujeito, do objeto do conhecimento, que se revela no contexto cultural em que a pesquisa se realiza, dado que os saberes se interconectam e interagem, favorecendo nossas reflexões.

Sob esse olhar, esta (e outras) pesquisa, de natureza qualitativa, é única, como também o são seus resultados, o que limita a sua generalização, prevalecendo a noção de que, não necessariamente, esses resultados possam ser transferidos ou replicados em outros contextos e circunstâncias, ainda que semelhantes (SOUZA et al., 2017).

Trabalhar nessa perspectiva nos permitiu reconhecer a validade dos conhecimentos e práticas cotidianas - suas singularidades e riquezas, que emergem das faltas, dos questionamentos e das imprevisibilidades, fazendo-nos compreender, de modo plural, os processos formativos em que estamos inseridos; o que se constituiu uma ação política, na medida em que entendemos que tais saberes são inseparáveis, exigindo coerência e consistência teoricometodológica.

Para Certeau (2013), Alves (2008) e Andrade, Caldas e Alves (2019), pesquisar com os cotidianos é procurar olhar, atentamente, em suas mínimas sutilezas, as artes do fazer cotidiano (muitas vezes silenciosas) dos praticantes ${ }^{4}$, que vivem a vida real, mergulhados nas ações ordinárias, nos detalhes, e no emaranhado das teias que os envolvem e formam. São essas artes do fazer que nos fornecem elementos para pensar os "fazeressaberes" dos praticantes da vida, em geral, e dos nossos professores, em particular, permitindo-nos compreender como se criam os conhecimentos e quais as contribuições das conversas no Whats $A p p$ ao processo formativo e autoral docente.

Com efeito, vivenciar a pesquisa com os cotidianos, na perspectiva da multirreferencialidade, é considerar que os caminhos da etnometodologia se cruzam com a

\footnotetext{
${ }^{4}$ Praticantes culturais, ou somente praticantes, são os indivíduos que realizam uma prática com determinado grupo, envolvendo-se com certo sentimento de identidade coletiva ao se relacionarem com os outros, por meio de um padrão de sociabilidade que os une (SANTOS, 2014; 2019)
} 
educação, resultando em etnométodos pedagógicos, ou seja, nas diferentes maneiras de fazer, interpretar e compreender o mundo, que dispensam explicações e justificativas científicas para se constituírem e se legitimarem nas ações práticas no dia-a-dia, propiciando o reconhecimento das interações sociais que se instituem.

Nesse contexto, conversas autorizadas dos praticantes ganharam destaque no WhatsApp, possibilitando-nos empreender sua análise, por meio da descrição, da interpretação e da compreensão do outro e de seu modo de "fazerconhecersentir".

A interpretação dos dados se desenvolveu ao longo do processo da pesquisa, no e com o movimento de nossas reflexões, alicerçadas em bases filosóficas, epistemológicas e metodológicas, possibilitando-nos, numa aventura pensada, exercitar um rigor outro, tendo em vista que a qualidade na pesquisa exige tanto refinamento no rigor, como novas formas de constituí-lo, como enfatiza Macedo (2010). Desse modo, "[...] significados e acontecimentos, recorrências, índices representativos de fatos observados, contradições profundas, relações estruturadas, ambiguidades marcantes" (p. 138) foram sendo percebidos, organizados e reunidos em categorias analíticas, a que denominamos noções subsunçoras.

Para o autor, essas noções emergem juntamente com a capacidade teórico-analítica do pesquisador, com base em sua experiência e em seu conhecimento prévio, em contato com a experiência do campo de pesquisa. Com isso, foram feitas leituras preliminares do material e estabelecimento de um rol de enunciados; escolha e definição das unidades analíticas: tipos de unidades, definição e critérios de escolha; a definição das noções subsunçoras propriamente ditas, e suas qualidades básicas; e a análise interpretativa dos conteúdos emergentes.

A exemplo da própria vida, pesquisar nos cotidianos, numa perspectiva multirreferencial, demanda assumir posicionamentos ético-políticos, todo o tempo. Para a multirreferencialidade “[...] a referência está no pesquisador, no objeto, no grupo, na escola, no campo de futebol, nas ciências da educação; enfim, na sociedade" (BARBOSA, 1998, p. 96). Desse modo, sempre haverá outro olhar, ou outros olhares e sentidos, que nos ajudarão a perceber e compreender o mundo.

Conscientes de que "[...] a formação se dá em conjunto, em dispersão, semelhante ao jogo da rede que se lança ao mar, sem certeza do que virá, mas com a convicção de que o ato é potência mobilizadora ao alcance de algo que se espera, se deseja" (RANGEL, 2018, p. 12), consideramos nossos praticantes culturais como coautores de nossos estudos. Sob esse ponto de vista, entendemo-nos como aprendizes da formação, considerando percursos já realizados e outros que se fazem no coletivo das redes, e 'fazeressaberes' estabelecidos, sem que tenhamos total clareza do quanto formamos ou fomos por eles formados.

\section{NA MAGIA DO INSTANTE, A EMERGÊNCIA DE APRENDIZAGENS MULTIRREFERENCIAIS E DE AUTORIAS}

Pensar as situações em que os praticantes culturais interagiam com as tecnologias digitais, seus modos de fazer e suas táticas foi uma aventura pensada. Na medida em que se atrela às narrativas que os praticantes fazem de suas vidas e as daqueles que as leem, o Whats App constitui um dispositivo de saber, dado que damos sentidos e significados às vozes desses praticantes cotidianos.

Assim, o uso do Whats App se justifica pelo dinamismo da formação, a partir das itinerâncias que percorrem, atravessam, relacionam, levando em conta a experiência autorizante e reflexiva do processo de aprendizagem (Macedo, 2010). Nesse "ir-e-vir sendo", no qual se desenvolvem as tramas entre individual e coletivo, é que ocorrem as dimensões da formação: a autoformação, a 
DOI: $10.12957 /$ teias. $\%$ Y.52666

heteroformação, a a erosformação, a ecoformação, e a (trans)formação (PINEAU, 1988; MACEDO, 2020).

$\mathrm{Na}$ autoformação, o sujeito se apropria do poder de formação. Autor do próprio processo formativo, trazendo, nessa dinâmica reflexiva as suas subjetividades, as referências pessoais, as relações com o outro e com o meio ambiente físico, dado que a dinâmica da autoformação não está desvinculada dos processos de heteroformação e ecoformação: somos praticantes culturais responsáveis por refletimos, criticamente, sobre os nossos "fažeressaberes" cotidianos no contato com o outro e mediatizados pelas interfaces cidade-ciberespaço.

$\mathrm{Na}$ heteroformação, o processo reflexivo está intimamente ligado às relações que estabelecemos com o outro, a nossa capacidade de empatia; o que nos constitui como praticantes culturais nessas conversas e experiências. Para Santos, R. (2015, p. 48), além de "[...] reconhecer o outro na formação, necessitamos demonstrar que o heterogêneo é um valor a ser cultivado, criando condições para que seja legitimado, sem que as relações entre as diferenças signifiquem esquecer o valor do bem comum social". Com efeito, a produção de sentido em relação à docência é possibilitada pelas experiências, mediatizada pelas especificidades do meio em que ocorrem. A erosformação, por sua vez, consiste na alegria, no prazer e na paixão pelo saber e por aquilo que fazemos, capaz de mobilizar forças criativas em direção a um objetivo pretendido.

No processo de ecoformação o meio ambiente atua na formação do indivíduo, possibilitando "[...] a conexão com o novo e o que necessita ser preservado e recuperado em termos humanos e planetários" (BARBOSA, 2018, p. 139). Nessa perspectiva, entre outros fatores, violência, pobreza, vulnerabilidade social, tecnologias digitais, influenciam, de forma substantiva, as possibilidades de autoformação, na medida em que o professor vai passando por um processo de transformação ao interagir com as necessidades que a experiência impõe.

Entendemos que a dinâmica não pode ficar circunscrita a reflexões solitárias, intimistas e/ou individuais. A partir dessas três dinâmicas formativas, e compreendendo que aprendemos com o outro, Macedo (2010) nos apresenta uma quarta: a (trans)formação. Os processos de interiorização alcançam sentido a partir da passagem de uma situação a outra. Identificamo-nos com algumas pautas de vida, estamos cientes de que precisamos fazer algo em relação às demandas que nos cercam, atravessando-nos, cotidianamente, e que não podem estar ainda circunscritas a especificidades disciplinares, ou como questões do outro. "Fazemos apenas uma opção pedagógica ou epistemológica pelo novo que altera, politizando eticamente a formação, numa escala humana dialógica mais ampla, para que, em formação, aprendamos como diferenças a viver juntos" (MACEDO, 2010, p. 76).

Ao manifestarmos nossos pensamentos em textos, áudios, imagens estáticas ou em movimento, e performances, entre outros formatos, ancorados em nossas memórias e em vozes que nos antecederam, atualizamos os discursos já existentes, criando nosso próprio espaço do dizer, de modo responsivo e responsável, enfatiza Amaral (2014). Com efeito, tornamo-nos autores, em potencial, o que exige, segundo a autora,

[...] a vivência da contingência e da incerteza, além de movimentos de construção, desconstrução e reconstrução, decorrentes do descentramento de pontos de vista e da necessidade de se confirmar, reorganizar, complementar, e/ou modificar, continuamente, saberes e comportamentos advindos das conexões entre objetos, eventos e pessoas, resultando novos modos de subjetivação no exercício autoral (p. 68-69).

Sendo assim, buscamos inspiração em Maddalena (2018, p. 143), que ao pesquisar o Digital Storytelling, optou por "[...] dar valor às experiências e vivências pessoais dos praticantes, para 
construir, a partir delas, relatos formativos". Desse modo, trouxemos as vivências ligadas às memórias dos docentes, destacando 'o que lhes passa, acontece e toca'; o que requer, como Larrosa (2004, p. 24),

$[\ldots]$ parar para pensar, parar para olhar, parar para escutar, pensar mais devagar, olhar mais devagar, e escutar mais devagar, parar para sentir, sentir mais devagar, demorar-se nos detalhes, suspender a opinião, suspender o juízo, suspender a vontade, suspender o automatismo da ação, cultivar a atenção e a delicadeza, abrir os olhos e os ouvidos, falar sobre o que nos acontece, aprender a lentidão, escutar os outros, cultivar a arte do encontro, calar muito, ter paciência e dar-se tempo e espaço.

Tocamos as reminiscências dos docentes, essas tantas lembranças que nos ocorrem quando contamos nossas experiências de vida e formação, visto que somos, parafraseando Ferraço (2007, p. 81), "[...] praticantes culturais de uma história passada recontada pelos sujeitos de hoje". Mas também somos parte de uma história presente, escrita por várias mãos, e ainda por ser contada pelos que virão.

Apresentamos, a seguir, algumas conversas estabelecidas com os professore, extraídas do grupo do Whats $A p p$, mencionado, anteriormente.

Professora-pesquisadora: "A frase q para mim é marcante e inesquecivel é " Me dá o seu e-mail?", porque na época q a ouvi pela 1 vez, eu não tinha computador e tbpq não entendi esse "e-mail". Fiquei com cara de tacho... torcendo os olhos, tentando entender o q a pessoa pedia? Era um doce, uma folha...'

atual?".

Valessa: "Tem que ser uma frase antiga, dos primórdios do uso da tecnologia? Ou pode ser uma mais

Edelzia: "Alguém, um belo dia, bá muito tempo, me perguntou: - qual é o seu navegador? Olhei pra pessoa e perguntei: - o que é isso?"

Valessa: "Um fato marcante na tecnologia foi o encerramento do MSN, melhor comunicador instantâneo já inventado em todas as épocas! Só eu arrumei 2 maridos conversando pelo MSN.

Uma frase (atual) que sempre me digo em relação a tecnologia é como as pessoas conseguiam viver sem smartphone?!”.

Professora-pesquisadora: "MSN, @Valessa? Isso foi antes das salas de bate papo da UOL?”.

Edelzia: "A melhor coisa é ver e conversar com minha neta mineira Alice, pelo aplicativo Imo, todos os dias. Leio bistórias pra ela. A distância diminui muito".

Professora-pesquisadora: "Fazíamos as amizades no chat UOL e de lá partiamos pra algo mais privado, o MSN".

"Faço todas as transações bancárias pelo app no cel. Só não tiro dinheiro pelo app pq não dá Nem nos investimentos eu vou ao banco, só

Professora-pesquisadora: "Apesar de ser smartphone". amante desse mundo tecnológico, ainda sou resistente ao uso do celular para esses fins, @Valessa!".

Martha Geo: "Minha frase marcante da época do chat da UOL: "quer tc? Achava bizarro, até entender o q significava demorou um pouco... kkkk eu tinha uns 14 anos".

Professora-pesquisadora: "Muito boa lembrança, Martinba!"

Karla: "Alguém lembra do ICQ e aquele barulhinho tipo ôou?!

E vc tinha que decorar o código dele que era um número! Foi antes do MSN!".

Flavinha: "Número maior $q R G$ ".

Daniele: "Eu faço pelo celular".

Professora-pesquisadora: "dava pra falar com isso? O q era?".

"Tenbo medo!". 
Daniele: "Tem que ter antivirus. É seguro!".

Karla: "O ICQ foi o primeiro desses programas de msg instantâneas!

bttps:// www.myinstants.com/ media/ sounds/icq-old-sound.mp3"'

Professora-pesquisadora: "Eu lembro desse barulho...".

Karla: "Kkkk. E o simbolo era uma florininha!".

Daniele: "Algo que me marcou, quando estudava no CEFET, \& \& \&ue aquela trabalheira toda que en tinha para fazer meus projetos de desenho, en poderia fazer tudo no AUTOCAD".

Professora-pesquisadora: "Nossa! Tantas lembranças... rsrs.

O Autocad continua caro!"

Daniele: "Ah... quando eu vi o primeiro CD. Achei extraordinário".

Professora-pesquisadora:"'.https://youtu.be/V1t_dC7E10w@Karladiretora, lembrei! (polegar apontado pra cima) Eu sou da época das salas da UOL...rsrs Ai me lembrei dos CD de disco, das buscas nas Lojas Americanas!

Acho q vou fazer uma linha do tempo só com as frases de vcs!

Jaqueline: "Para mim, foi a passagem dos computadores de grande porte

Obrigada!". para os notebooks. Eu diria: como tudo irá caber aí? Não vai funcionar. Atualmente temos os pendrive de 1G. (carinha com língua e olho arregalado, carinha piscando)"

Professora-pesquisadora: E agora tudo cabe em um celular, né, Jackie?! Tudo bem q estão cada vez. mais caros... Eu conheço pessoas q estão sonhando com um iPhone 8 de presente de Natal!"

MarthaGeo: "TCQ 응 ...foi o início do namoro com meu marido, pelo ICQ nas

Celia5: "Eu acho que nessa era da tecnologia o que marcou para mim foi quando

férias!" acontecen a migração do orkut para o Facebook, porque o Facebook estava fazendo muito sucesso e as pessoas falavam assim: Você tem Facebook? Porque só pode ter Facebook se você for convidada. Então, automaticamente, se você não fosse convidada pro Face era alguma coisa como se você se sentisse excluido, né? Então pra mim isso foi marcante: a migração do orkut para o Facebook.".

Flavinha: "Agora é O!!!!!”.

Valessa nos apresenta pistas do que, possivelmente, iremos encontrar ao longo das conversas: "Tem que ser uma frase antiga, dos primórdios do uso da tecnologia? Ou pode ser uma mais atual?" Dessas conversas, portanto, emergem experiências cotidianas, em tempos diversos, constituídas de diferentes e múltiplos processos subjetivos, dado que cada realidade age de modo distinto sobre os sujeitos, que a interpreta, também, de forma diferenciada. $\mathrm{O}$ relato dessas experiências evidencia como as mídias digitais têm evolú́do, ao longo do tempo; o que vai ao encontro do pensamento de Calvão, Pimentel e Fucks (2014), que entendem essas mudanças como decorrentes de um processo de evolução, a partir de funcionalidades que foram sendo acrescentadas, removidas ou alteradas.

No início da conversa, a professora-pesquisadora relata sua impressão diante da pergunta que lhe marcou: "Me dá o seu e-mail?", revelando a dificuldade que sentiu para compreender algo que ainda não era prática na vida das pessoas: o envio e o recebimento de mensagens via internet. Mal sabia ela que a troca de email iria dar lugar a uma nova cultura de envio e recebimento de mensagens, com mais rapidez e informalidade do que as cartas. Hoje, receber uma correspondência pessoal via correio, tornou-se algo raro; em geral, restrito às cobranças e comunicados de empresas (CALVÃO, PIMENTEL, FUCKS, 2014).

${ }^{5}$ Celia não é professora do grupo da Escola. Como fizemos essa pergunta para outros grupos e consideramos uma resposta interessante, pois já traz a ideia de rede, acrescentamos sua visão a nossa conversa.

Revista Teias v. $22 \cdot$ n. $65 \cdot$ abr./jun. 2021 
Como podemos constatar, as mídias digitais não apenas trazem mudanças na forma como nos relacionamos, como permite que nos apropriemos de palavras, acepções e conceitos que antes não existiam. "Qual é o seu navegador? O que é isso?" Que sentidos e significados podem ter passado pela mente da professora Edelzia ao verbalizar a sua dúvida? A palavra 'navegador' jamais fora usada no sentido de ser um programa de acesso a uma página da Internet, por isso, ocasiona certa estranheza. Ao mesmo tempo, conserva traços de seu significado original ao permitir que, ao ser ponte entre usuário e conteúdo digital, possamos navegar entre as páginas, descobrindo outros saberes.

Nessa mesma perspectiva, encontramos os emojis, o 'curtir' e seus múltiplos sentidos que, inicialmente, nos causavam certo desconforto. Como não se confundir com as várias possibilidades de usos da palavra 'curtir', que não apenas serve para demonstrar que gostamos de algo, mas também para informar que tomamos ciência do que foi postado? Ou seja, as mídias digitais possibilitaram, também, o surgimento de novos gêneros textuais, outras formas de expressão, para dar conta de algumas intencionalidades discursivas.

Recuero (2014, p. 49) pontua que esses “[...] usos oferecem espaços de construção de práticas que vão ampliar a negociação de sentidos de seus usuários, criar convenções (como os emoticons $s^{\sigma}$ e ajustar contextos que vão permitir a conversação". Por outro lado, Karla, Valessa, MarthaGeo e Edelzia, praticantes de nossa pesquisa, ajudam-nos a dialogar, com a autora, ao relembrarem os aplicativos de mensagens $I C Q^{7}, M S N^{8}$, as salas de bate-papo da $U O L^{9}$ e o $I M O^{10}$, bem como pensar sobre as potencialidades interativas que esses dispositivos proporcionam às pessoas.

À medida que evoluem os meios de conversação, os praticantes se tornam 'menos espectadores', dado que a disposição interativa permite ao usuário ser ator e autor, fazendo da comunicação não apenas o trabalho da emissão, mas cocriando a própria mensagem e a comunicação, como assevera Silva (2003, 2014); ou seja, os praticantes culturais têm maior controle de suas ações.

A conversa dos docentes sobre as próprias vivências e experiências ligadas aos usos da tecnologia, "[...] partilhando saberes, intervindo no discurso do outro, produzindo coletivamente a mensagem, a comunicação e a aprendizagem" (SANTOS, 2005, p. 115) materializa os três fundamentos da interatividade sugeridos por Silva (idem): a bidirecionalidade dialógica, a participação colaborativa e as conexões em teias abertas, possibilitando que os indivíduos consumam, produzam, colaborem e cocriem a informação.

Outro ponto a destacar, e não menos importante, é a presença dos aplicativos na cibercultura, aqui entendida como a cultura contemporânea na qual a comunicação, a produção e circulação de informações e conhecimentos se dão na interface cidade-ciberespaço, e de onde emergem novos arranjos "espaçostemporais" e novas práticas educativas e de formação (SANTOS, 2014; 2019). Em certo momento, Edelzia nos relata, com alegria, o prazer em ver e conversar com a neta mineira, e poder contar histórias tendo a sensação da diminuição desse distanciamento

\footnotetext{
${ }^{6}$ Representação gráfica de uma emoção feita através dos caracteres que você tem à disposição em seu teclado.Muito usados em locais em que você só pode usar texto para se comunicar.

7ICQ - Disponível em https://www.techtudo.com.br/dicas-e-tutoriais/noticia/2016/05/o-que-e-icq.html. Acesso em 22 fev 2019.

${ }^{8} \mathrm{MSN}$ - Disponível em https://br.ign.com/msn-1/62363/feature/5-anos-sem-msn-o-programa-de-mensagem-maiscompleto-que-ja-e. Acesso em 22 fev 2019.

${ }^{9}$ Bate-papo UOL - Disponível em https://www.tecmundo.com.br/brasil/118052-entramos-bate-papo-uol-2017saber-ainda-acontece.htm. Acesso em 22 fev 2019.

${ }^{10} \mathrm{IMO}$ - Disponível em https://www.techtudo.com.br/tudo-sobre/imo.html. Acesso em 22 fev 2019.
} 
familiar. São os aplicativos que nos permitem organizar as nossas vidas, viver com mais facilidade e diversão.

Custa-nos acreditar, em tantas mudanças em tão pouco tempo, como nos lembra a professora Jaqueline, referindo-se à impressão que lhe causou, à época, a passagem dos computadores de grande porte para os notebooks, em "Como tudo irá caber aí? Não vai funcionar!", e, hoje, concluir: "Pois funcionou, e cabe tudo na palma da mão". Com efeito, hoje, navegamos em busca da melhor página, da rede social que mais faz sucesso, ou desperta curiosidade; por interesse ou pela necessidade que sentimos de fazer parte de um grupo. Celia reflete bem a noção de pertencimento, que se configura como um traço do contexto contemporâneo: migramos de um lugar para outro, de uma interface à outra, à procura de um lugar que nos acolha, nos receba, e nos inclua.

Concordamos com Calvão, Pimentel e Fuks (2014) quando afirmam que a todo momento surgem novos sistemas de conversação que ameaçam desbancar aqueles que ocupam posição de destaque, ao trazerem funcionalidades inovadoras; consequentemente, atraindo novos usuários. Foi assim com o Whats $A p p$, dispositivo, que se popularizou ao permitir que as pessoas pudessem participar de grupos de conversa, desde que fossem convidadas. A ideia inicial é que houvesse uma relação de mais intimidade e segurança, bandeiras defendidas por Koum e Brian Acton, fundadores do Whats App, mas, hoje, esses usos têm tomado outros rumos.

No próprio grupo dos professores, por diversas vezes, houve compartilhamento de mensagens que depois se revelaram falsas ou boatos e, com o tempo, surgiu outro tipo de prática e uma pergunta que na época da conversa acima ainda não havia surgido, mas que já circulava entre as conversas: "Gente!! Deve ser boato! Ou melhor, "É Fake News?"

Will: "Acabamos de receber a informação de que o traficante Lambari, que comanda a região do Jacaré e Jacarezinho, pertencentes ao Comando Vermelho, ordenou a saida de traficantes oriundos do Complexo do Chapadão das regiões sobre o seu comando...

Esse menor que morreu é filho do dono do Morro, que tá preso.

A rota dessa guerra será compreendida entre Costa Barros, Madureira, Campinho, Cascadura, Abolição, Maria da Graça, Méier e Jacaré.

Evitem sair de casa bj principalmente para a Suburbana, o Norte Shopping, Abolição, linha amarela, Madureira e adjacências. A inteligência da polícia federal descobriu que os bandidos do Jacaré estão saindo para apoiar os bandidos de Madureira. REPASSEM.

Recebi essa mensagem, mas como está tudo normal, ai na escola, acho que pode ser $\quad$ boato".

Claudia: "Karla, liga pro Macarrão pra confirmar se é boato!"

Renatio:

Valessa: “Lambari... Tem família estudando lá no meu ex-Ciep! Minha mãe deu aula pro sobrinho dele".

Fátima: "Gente!! Deve ser boato p apavorar o povo!! Por Deus,viu?!! Precisam "brincar é coisa Séria" os boateiros de plantão. Mas na dúvida, rsrs ..tds em alerta, eita!! O q aliás já é rotina. aff!!".

Valessa: "Acredito em qualquer coisa desse gênero em relação ao Hell de Janeiro.

O que acho mais inverídico nessa msg é que "a inteligência da PF descobriu..." Eles mesmos, a bandidagem, espalham esse tipo de informação. Mandam até 'representante' na escola avisar".

Fátima: "É vdd...p. isso q agente sabe qdo tem cara de boato... .Eles realmente nem precisam de boato msm. Fazem acontecer.. Mais LUZ e AMOR! Mta LUZ!! p todos nós!! e p nosso Brasil!!”.

Tornou-se imprescindível checar as informações e, para facilitar essa ação, agências de comunicação lançaram serviços esclarecendo às pessoas da veracidade das informações. Ferrari (2018) aconselha-nos a desconfiar de tudo, e reforça a necessidade de se discutir sobre verdade e 
critérios éticos na escola, na universidade, na igreja, e no clube, por acreditar no papel social de cada educador.

Com efeito, o combate a essas práticas não é nada fácil; pressupõe a construção de valores baseados na liberdade e na diversidade. No entanto, de acordo com o Comitê Gestor de Informática $^{11}$ (CGI.br), é possível adotar algumas medidas para evitar que notícias falsas, ou descontextualizadas, tomem corpo, tais como desconfiar de títulos bombásticos; pensar antes de clicar; verificar as fontes; duvidar de informações compartilhada sem referências; e, em caso de dúvida, não compartilhar e não se calar.

Por outro lado, para lidar com o mundo virtual, os indivíduos precisam buscar a qualidade da informação veiculada na Internet, o que implica desenvolver seu potencial reflexivo e crítico, ou seja, a capacidade de pensar para obter o conhecimento em sua interação com esse meio.

Não há dúvidas de que o alinhamento entre educação e tecnologia constitui uma necessidade premente da escola, para responder aos desafios contemporâneos de uma aprendizagem hipertextualizada, possibilitada pela criatividade humana de propor invenções, em resposta às necessidades que emergem nos cotidianos escolares. Bem sabemos que as tecnologias digitais são utilizadas pelos professores em suas práticas cotidianas. No entanto, faz-se necessário utilizar esses dispositivos, nos processos de 'aprendizagemensino', entendendo-os como aliados, na apropriação do conhecimento, de forma colaborativa, tendo em vista transformar a realidade, pois a educação, para fazer diferença na/para a vida das pessoas, precisa de menos prescrição e mais articulação, produzindo, interagindo, colaborando e compartilhando informações e conhecimentos. Para aproveitar as potencialidades dos usos das tecnologias, alguns professores inventam outras formas de produzir conhecimento, como podemos observar nos relatos dos professores Giannis, e Orlando e da Professora-pesquisadora:

Giannis: "Desenvolvo o projeto do jornal, que envolve o uso de câmera e software de edição de fotos e vídeos com grupo restrito de alunos, além do uso de apresentações em Power point e do Google Earth na apreensão elementos geográficos por meio de imagens de satélite”.

Professora-pesquisadora: "Nos projetos que desenvolvi com os alunos, trouxe para o centro das apresentações o uso do notebook, do datashow, do aparelho de som e do celular. Alguns grupos pesquisavam e registravam na forma tradicional, nos cadernos, mas começaram a surgir grupos que gravavam e sistematizavam os trabalhos no tablet ou celulares. As aulas tornaram-se mais dinâmicas e também surgiu a necessidade de refletirmos sobre a lei que impedia o uso do celular em sala de aula. Na lei não havia explicitada a proibição do uso do celular para fins educativos e, por isso, após algumas negociações e acordos, o uso do smartphone e de outros dispositivos móveis tornou -se uma constante durante a elaboração das tarefas coletivas e no momento da apresentação dos trabalhos".

Orlando: "Costumo utilizar caixa de som em sala. Só preciso de uma tomada, conecto via cabo RCA ao meu tablet ou celular. Em alguns momentos utilizo o projetor e conecto a imagens do meu tablet, projeto imagens de vídeos fotos e aplicativos interativos, tudo plugado à caixa de som".

As conversas no grupo refletem e retratam as experiências dos praticantes, as leituras, as concepções de mundo, buscando questões que afetam nossas vidas. O trabalho com a tecnologia, especialmente, com os dispositivos móveis, facilita o convívio entre alunos e professores. É fundamental percebermos que o aluno é capaz de assumir a responsabilidade pelo seu processo de aprendizagem quando estimulamos a pesquisa, a elaboração de trabalhos, a construção da reflexão; brincando e incentivando a curiosidade e o lúdico.

\footnotetext{
${ }^{11}$ Informações sobre o Comitê Gestor de Informática. Disponível em https://cgi.br/. Acesso em 19 fev 2019.
} 
Além disso, por ser um local marcado por um entorno muito violento, com relatos constantes de assaltos, mortes, confrontos entre grupos rivais e enfrentamento policial, o grupo do Whats $A p p$ constitui-se num espaço de troca de mensagens que não dissocia o "dentrofora" da escola. Nas conversas a seguir, é possível observar a diversidade de histórias que emergem no uso do aplicativo, os dilemas docentes e o quanto eles afetam as relações, no cotidiano escolar e nos modos de viver e de "aprenderensinar".

Flávia: "BOM DIA, PROFESSORES! ALGUNS RESPONSÁVEIS ESTÃO PROCURANDO A DIREÇAO, PREOCUPADOS COM AVALIACOÕES QUE ESTAVAM MARCADAS NESTE PERÍODO DE CONFLITOS, NO JACARÉ. PEÇO QUE REMARQUEM SEGUND AS CHAMADAS PARAQUE NOSSOS ALUNOS NAOO FIQUEM PREJUDICADOS”.

Douglas: "Perfeito, mas... e, com relação a algum tipo de reposição da matéria... Isto está sendo planejado nas escolas que estão fechadas... Temos turmas com quase 50\% de ausência. Como lidar com a matéria nova, que está sendo perdida?".

Daniele: "Douglas, hoje a escola está cheia. Dia normal. Agora é acelerar e dar os conteúdos que ainda não foram trabalhados".

Gilmar: "Eu levantei esta questão, pois teríamos um periodo de tempo tão curto para dar avaliação de recuperação paralela com as operações policiais".

Douglas: "Exatamente, Gilmar... O periodo passou e muitos ficaram sem a possibilidade... As escolas fechadas estão amparadas... A nossa que também sofreu com a questão, nenbuma palavra da CRE de como proceder.

Desculpe, amiga Daniele, a escola pode estar cheia, mas ainda não está normal... O Jacaré ainda está apinhado de Militares, faz̧endo revista até em crianças... Reclamamos tanto da irresponsabilidade de alguns responsáveis que mandavam as crianças às escolas... Considero ainda arriscado ficar passeando na comunidade, próximo aos militares, podendo ter trocas de tiro a qualquer momento. Não mandaria meu filho à escola. Ainda não está nada normal. Se estivesse normal, não haveria 15 escolas fechadas".

Professora-pesquisadora: "Boa noite! A preocupação do Douglas é de todos! Na próxima semana teremos o Centro de estudos, momento para pensarmos sobre as questões levantadas acima. Talvez seja um momento para refletirmos sobre a maneira como avaliamos, acolhemos, escutamos e lidamos com os nossos alunos, depois de dias de tanta violência nessa região".

Como vimos, os acontecimentos atravessam a escola, sem lhe pedir licença. O fato de haver, ou não conflitos, na comunidade, é o que define o fluxo do trabalho, dado o esvaziamento das aulas. Devido à dificuldade de acesso à escola, avaliações são remarcadas, exigindo o replanejamento das atividades curriculares. Como lidar com a matéria nova, que está sendo perdida? Como, num período, tão curto, dar avaliação de recuperação paralela, com as operações policiais? são preocupações presentes nas narrativas de Douglas e Gilmar.

Douglas: "GENTE, PRECIS AMOS DEBATER UMA QUESTÃO IMPORTANTE... DIREC $\tilde{A O}$, precisamos tmb ver o que faremos diante das operaçōes que ocorrem no Jacarezinho...".

Estou sendo chamado aqui por Messenger por alguns alunos, que por mais que nossa escola, o prédio, não esteja no foco do problema, alguns de nossos alunos estão... A Aluna Maria é uma delas, e está preocupada por saber que perdeu matéria, e que tem uma prova está semana.

Vimos que na reunião com secretário, as escolas no front estão fechadas e com várias estratégias de reposição para os alunos. E para os nossos, que não podem sair de casa, pois sofrem risco de morte? O que faremos? Fica a questão...”.

Como enfatiza Douglas, bem sabemos que as escolas em fronteiras de favelas dominadas por traficantes rivais têm um desafio ainda maior no contexto da educação em áreas conflagradas 
pela violência urbana, mas não podemos desconsiderar, dessa análise, as escolas que se localizam fora desse contexto, e que recebem alunos oriundos desses territórios. Logo, observamos a preocupação dos professores nessas conversas com a situação que se apresenta, principalmente, quando há diferença de tratamento entre as escolas de fora e as de dentro desses territórios instáveis; o que requer pensar em estratégias que deem garantias aos alunos oriundos das duas realidades que se apresentam.

Essas conversas refletem e retratam as experiências dos praticantes, as leituras, as concepções de mundo, buscando questões que afetam nossas vidas. O trabalho com a tecnologia, especialmente, com os dispositivos móveis, facilita o convívio entre alunos e professores. É fundamental percebermos que o aluno é capaz de assumir a responsabilidade pelo seu processo de aprendizagem quando estimulamos a pesquisa, a elaboração de trabalhos, a construção da reflexão; brincando e incentivando a curiosidade e o lúdico.

Nos espaços multirreferenciais de aprendizagem, os sujeitos ensinam e aprendem, tecem a autoria de suas produções e têm autonomia coletiva para compreender o significado de sua participação na sociedade. Desse modo, tem sido crescente, a produção de conteúdos, mediante intervenções diretas, ou interagindo com outros, em redes educativas, presenciais e online. Nessa perspectiva, o uso dessas tecnologias digitais como dispositivos de aprendizagens multirreferenciais e autorais no contexto da cibercultura pode inspirar outras práticas para que, no encontro com outras vozes, torne-se um instrumento de resistência, reivindicações, conquistas e formação.

\section{CONSIDERAÇÕES FINAIS}

Como vimos, este artigo, que teve como fonte de inspiração pesquisa realizada numa escola pública do município do Rio de Janeiro, buscou compreender como as conversas entabuladas no Whats $A p p$ por professores, podem contribuir para seus processos formativo e autoral, dado que, no contexto educacional, o uso desse aplicativo tem se intensificado, em complemento ao trabalho docente, ainda que, esse uso seja limitado na formação continuada dos professores.

Ao trazemos essas conversas para o centro dos debates, tínhamos consciência que não seria uma tarefa das mais fáceis, pois geradora, no meio acadêmico, de controvérsias, principalmente nos grupos que defendem os modelos racionalistas e hegemônicos de fazer ciência. No entanto, ao levar em conta a natureza multicultural e multissocial dos fenômenos e objetos que envolvem o estudo, nossa escolha se mostrou profícua, na medida em que nos possibilitou compreender como os 'fazeressaberes' docentes acontecem nos cotidianos.

Compreendemos que os relatos de memórias, de experiências, bem como as histórias que se cruzaram merecem uma nova escrita, mais delicada e cuidadosa, porque tecida por muitas vozes e mãos. No movimento de "ir-e-vir sendo", o processo formativo vai se instituindo e desenvolvendo, seja na relação docente com o outro, com os objetos e eventos, ou consigo próprio, produzindo 'sentidossignificados', numa perspectiva multirreferencial.

Vimos que as conversas fornecem indícios que nos ajudam a identificar quais são as forças atuantes nesses campos, as partes que se desagregam, aspectos de exclusão e de inclusão, deslocamentos e apropriações e, como isso tudo interfere nos processos de aprendizagem dos alunos; o que demandou escuta e olhar sensíveis para não apenas conhecermos os limites dos usos dos dispositivos móveis, mas, também, a necessidade de absorvermos em nossas práticas, valores baseados na liberdade de expressão, respeito, ética, considerando as múltiplas diversidades do Ser.

Isso nos levou a entender que não é possível analisar as tecnologias digitais dissociadas do contexto sócio-histórico em que se inserem. A qualidade da educação passa por desenvolver no 
leitor seu potencial reflexivo, crítico, ético e a capacidade de pensar para obter conhecimento na atual cena sociotécnica. Destacamos, ainda, que educar é um ato político e, como tal, não é neutro nem indiferente aos fenômenos e eventos que atravessam os cotidianos escolares.

Essas conversas que desnudam as diversidades, as diferenças e as desigualdades, atravessando-nos e nos inquietando, reverberam nos cotidianos escolares, tornando-se imprescindível uma prática curricular que dê conta de educar na atual dinâmica cibercultural. Nesse sentido, a escola precisa rever seu papel, abrindo espaço para discussões de assuntos concretos e pertinentes aos novos conhecimentos que vêm surgindo na sociedade, a fim de acompanhar as transformações emergentes, apropriando-se da riqueza das interações e da diversidade cultural possibilitadas pelo uso do digital em rede.

Ao trazermos o dispositivo Whats $A p p$ para a pesquisa, observamos as narrativas tecidas em um espaço reduzido, mas que, ao mesmo tempo, torna-se do tamanho do mundo pela abrangência dos temas tratados. Todas essas constatações permitem-nos concluir que o uso da interface pelos docentes favorece a tessitura de histórias, narrativas de um fazer em construção e, pelas características do aplicativo, as vozes dos praticantes reverberam nas vozes dos outros praticantes.

\section{REFERÊNCIAS}

ALVES, Nilda. Decifrando o pergaminho: os cotidianos das escolas nas lógicas das redes cotidianas. In: Oliveira, Ines Barbosa; Alves, Nilda(orgs.). Pesquisa nos/dos/com os cotidianos das escolas. Petrópolis: DP et al, 2008, p. 15-38.

AMARAL, Mirian Maia do. Autorias docente e discente: pilares de sustentabilidade na produção textual e imagética em redes educativas presenciais e online. Tese (Doutorado em Educação) - Universidade Estácio de Sá - Rio de Janeiro, 2014.

ANDRADE, Nívea; CALDAS, Alessandra.; ALVES, Nilda. Os movimentos necessários às pesquisas com os cotidianos - 'após muitas conversas acerca deles'. In: Oliveira Ines Barbosa; Peixoto, Leonardo.; Süssekind, Maria Luiza. (orgs). Estudos do cotidiano, currículo e formação docente: questões metodológicas, políticas e epistemológicas. Curitiba: CRV, 2019, p. 19-45.

BARBIER, René. A pesquisa-ação. Trad. Lucie Didio. Brasília, DF: Plano, 2007.

BARBOSA, Alexsandra. Docência online: uma pesquisa-formação na cibercultura Dissertação de Mestrado. Faculdade de Educação, Universidade do Estado do Rio de Janeiro, UERJ, Rio de Janeiro, 2018.

BARBOSA, Joaquim Gonçalves (Coord.). Revisão de tradução Barbosa, Joaquim Gonçalves; Macedo, Roberto Sidnei Multirreferencialidade nas ciências sociais e na educaşão. São Carlos: UFScar, 1998. CALVÃO, Leandro; PIMENTEL, Mariano; FUKS, Hugo. Do email ao Facebook:uma perspectiva evolucionista sobre os meios de conversação da Internet. UNIRIO, 2014.

COLACIQUE, Rachel. Visualidades surdas na cibercultura: aprendizagens em rede. Tese de Doutorado. Universidade do Estado do Rio de Janeiro - PROPED/UERJ, 2018.

COUTO, Edvaldo; PORTO, Cristiane; SANTOS, Edméa. App-learning: experiência de pesquisa e formação. Salvador: EDUFBA, 2016.

CERTEAU, Michel de. A invenção do cotidiano: artes de fazer. 20ª ed. Trad. de Ephraim Ferreira Alves. Petrópolis: Vozes, 2013.

FERRAÇO, Carlos Eduardo. Pesquisa com o cotidiano. Educação e Sociedade. Campinas. Jan./abr. 2007, v. 28, no 98, p. 73-95. Disponível em http://www.scielo.br/pdf/es/v28n98/a05v2898.pdf. Acesso em 02 fev. 2020.

FERRARI, Pollyana. Como sair das bolhas. São Paulo: Educ/Armazém da Cultura, 2018. 
DOI: $10.12957 /$ teias. $\%$ Y.52666

JESUS, Rosana Salles. Conversas docentes no WhatsApp: uma pesquisa multirreferencial com os cotidianos. 2019. Dissertação (mestrado em Educação, cultura e comunicação) - Faculdade de Educação da Baixada Fluminense, Universidade do Estado do Rio de Janeiro, Duque de Caxias, 2019.

LARROSA, Jorge. Linguagem e educação depois de Babel. Trad. de Cynthia Farina. Belo Horizonte: Autêntica, 2004.

MADDALENA, Tania Lucia Digital storytelling: uma experiência de pesquisa-formação na cibercultura. Tese (Doutorado) - Universidade do Estado do Rio de Janeiro. Faculdade de Educação, 2018.

MACEDO, Roberto Sidinei. Compreender/mediar a formação: o fundante da educação. Brasília, DF: Liber Livros, 2010.

PINEAU, Gaston. A autoformação no decurso da vida: entre hetero e a ecoformação. In: Nóvoa, António.; Finger, Mathias(orgs.). O método (auto)biográfico e a formação. Lisboa: Ministério da Saúde, 1988.

RANGEL, Leonardo. Prefácio. In: Santos, E.; Caputo, S. (orgs). Diário de pesquisa na cibercultura: narrativas multirreferenciais com os cotidianos. Rio de Janeiro: Omodê, 2018.

RECUERO, Raquel. Redes sociais na Internet. Porto Alegre: Sulina, 2009.

SANTAELLA, Lúcia. A ecologia pluralista da comunicação: conectividade, mobilidade, ubiquidade. São Paulo: Paulus, 2013.

SANTOS, Edméa. Educação online: cibercultura e pesquisa-formação na prática docente. Repositório institucional UFBA. 2005.200 Disponível http://www.repositorio.ufba.br:8080/ri/handle/ri/11800. Acesso em 04 fev. 2019.

SANTOS, Edméa (org.). Pesquisa-formação na cibercultura. Portugal: Whitebooks, 2014.

SANTOS, Edméa (org.). Pesquisa-formação na cibercultura. Teresina: EDUFPI, 2019.

SANTOS, Rosemary. Formação de formadores e educação superior na cibercultura: itinerâncias de grupos de pesquisa no Facebook. Tese de Doutorado. Faculdade de Educação, Universidade do Estado do Rio de Janeiro, UERJ, Rio de Janeiro, 2015.

SERPA, Andrea. Quem são os outros na/ da avaliação? Caminhos possíveis para uma prática dialógica. Tese (Doutorado em Educação) - Faculdade de Educação. Niterói, Universidade Federal Fluminense, Niterói, 2010.

SILVA, Marco (org.). Educação online: teorias, práticas, legislação e formação corporativa. São Paulo: Loyola, 2003.

SILVA, Marco. Sala de aula interativa. $7^{a}$ ed. São Paulo: Loyola, 2014.

SOUZA, Adail; CORREAA, Dalila; NOBRE, Fábio; PADOVESZE, Clóvis. Brazilian Journal of Development. Curitiba, dez. 2017, v. 3, no. esp, p. 465-480. Disponível em

https://w2files.solucaoatrio.net.br/atrio/upe-papgef_upl//PRODUCTION/891/

artigo b2 brazilianjournalofdevelopment 2020 20200828123221696.pdf. Acesso em 03 dez. 2020.

SPINK, Mary Jane; BRIGAGÃO, Jacqueline; NASCIMENTO Vanda; CORDEIRO, Mariana (orgs.). A produção de informação na pesquisa social:compartilhando ferramentas. Rio de Janeiro: Centro Edelstein de Pesquisas Sociais, 2014 (publicação virtual). 
DOI: $10.12957 /$ teias.\%Y.52666

\section{Informações das autoras}

Rosana Sales de Jesus

Faculdade da Baixada Fluminense da Universidade do Estado do Rio de Janeiro - UERJ- FEBF/UERJ

E-mail: rosana.sales@terra.com.br

ORCID: https://orcid.org/0000-0003-3467-0726

Link Lattes: http://lattes.cnpq.br/52630 61694046936

Mirian Maia do Amaral

Fundação Getúlio Vargas - FGV

E-mail: amaral3378@gmail.com

ORCID: https://orcid.org/0000-0002-9472-7571

Link Lattes: http://lattes.cnpq.br/6493381786772205) 